\title{
Act V
}

\section{Nancy Stone}

I stand at the open window looking down two stories through waves of heat at a glob of phlegm frying on the pavement. It gleams new and fresh in a surround of old stains. I saw the mouth it came out of just a minute or two ago, a hole in the face of a dirty old man, a wino perhaps. I push the gauzy glass curtain aside to have a clearer view. It looks like the spittle of a wino. The snot he blew out of his nose is at the base of a lamppost fifteen feet beyond. The phlegm was placed with the ease of Billy Jean King hitting a tennis ball. Zap and it was there. The depositing of the snot was a delicate operation more like brain surgery than tennis. I don't look at it. I do look at the glob the dirty old wino hoicked from the back of his throat and wonder what poisons teem through it. I think back to high school, of a boy I knew who hung on the fringes of my crowd one year, the year he had a new blue Buick Skylark convertible. His name was Hoyt. He was called Hoick. But he didn't mind, for he had the privilege of driving us around in his Skylark. At the very second that my mind is full of Hoick and hoick cooking on the sidewalk two stories below, you slide the fingers of your right hand over the fingers of mine. I feel your breath on the back of my neck. It blows softly on a scar, a dime-sized white spot. You aren't touching me, elsewhere, but you are close enough for me to feel the charge your body emits. I did not notice your erotic sizzle when you came into the room, so great was my concentration on some of the small importances of hoick. This is the anniversary of our wedding that took place one year and two hours ago in this city in this hotel. You say nothing, my communard, and I'm glad, for your voice is like the sound of a quick stream oiling its way over flat smooth rocks. I know without seeing that you are looking over my head, looking down at the street. That you don't see what I see clearly-the whitecaps in a sea of spittle, as clearly as a child sees. I might say that I too am close to the ground, so to speak. Likewise, you are not. I won't say it. I might have said it, though, six months ago. I might even have tried to paraphrase it last week. Today I would never attempt it. Today I focus without saying on life's small scenes: a glob of spit frying on the sidewalk, 
a string of snot wrapped around the base of a lamppost. My life has been too full of the broad picture, the investment in futures, the long run, haul, the deduction, the bottom line. Today is the bottom line. You still do not speak and I'm glad. I wish I didn't feel your breath on my neck scar or your fingers intersticing mine. I think of your right fingers separately. I have traced them with mine remarking their bluntness and brownness and thought how each has grasped and probed the parts of a body not its own. Your hand leaves mine; its dry imprint remains.

Darling, you say, your voice like a stream oiling over green rocks.

Darling, I say, flatly smoothly.

Both your hands grasp my shoulders. Your blunt brown fingers dig at my clavicle.

Don't say it, I say.

You know, of course, don't you, Darling, you say.

So like me isn't it, I say. I know without your saying. Darling.

In this moment the sun falls below the skyline. The shadow of the buildings across the street sucks the curtain outward. The splash of phlegm on the sidewalk ceases bubbling. It begins to look more like the older stains surrounding it. The snot that insistently infested the periphery of my sight no longer has light to catch. It dries.

There'll be a storm before sunset, you say, and your left arm shoots over my shoulder. My eyes raise to your pointing finger. A bruise has appeared where the buildings touch the sky. It spreads over gangrenous streaks that are the only visible signs of this day's sun setting behind the city.

Come away from the window, you say.

Why, I say, turning my back and coming from the window.

Your hands are fists and the knuckles press into my shoulder blades. Your breath strokes my lips. I have closed my eyes. Behind them the spittle continues to bubble. I know I will never erase it from my mind. It is there forever, like Hoyt, to recur when someone I love is trying to make me see the broad picture.

Look at me, Darling, you say.

I open my eyes and your smiling face is as inscrutable as a card catalog in a strange library. I have wondered how this could be so when I know in my heart that all card catalogs are the same. And that I'll always remember Hoyt/Hoick with emotion. He will stand along with the memory of my fingers tracing your brown blunt ones. Your fists relax and slide off my back. Your fingers are engaged in unbuttoning the front of my blouse beginning with the bottom buttons. As you unbutton, I button. At the top button, our fingers struggle. Open or closed?

Darling, you say.

The first drops of a late afternoon summer shower burst on the stained pavement below our window like distant applause. 